\title{
Endocrine disrupting potency and toxicity of novel sophorolipid quaternary ammonium salts
}

\author{
Ewa Liwarska-Bizukojc $\mathbb{D}^{1} \cdot$ Christian V. Stevens $^{2} \cdot$ Elisabeth I. P. Delbeke ${ }^{2} \cdot$ Kevin M. Van Geem ${ }^{3}$
}

Accepted: 23 February 2021 / Published online: 17 March 2021

(c) The Author(s) 2021

\begin{abstract}
A new class of biosurfactants, namely quaternary ammonium sophorolipids (SQAS), suitable for pharmaceutical applications, was tested for the evaluation of their (anti)estrogenic and (anti)androgenic potency with the help of YES/YAS assays. Also their toxicity towards yeasts (Saccharomyces cerevisiae) and bacteria (Escherichia coli) was checked. The results achieved for SQAS, which can be regarded as potential micropollutants, were compared with those obtained for two well-known micropollutants diclofenac and $17 \alpha$-ethinylestradiol subjected to the same testing procedures. This work demonstrated that acetylation of the hydroxyl group of the carbohydrate head of SQAS decreased the toxicity of this class of biosurfactants towards Saccharomyces cerevisiae. Furthermore, it contributed to the decrease of their endocrine disrupting potency. None of the SQAS studied showed clear agonist activity for female or male hormones. SQAS1 and SQAS2 revealed weak antiestrogenic and antiandrogenic potency. All of these properties were weaker, not only to the potency of the appropriate positive control in the antagonists bioassays, but also compared to the potency of other tested compounds, i.e. DCF and EE2. SQAS3 possessed most probably inhibitory activity towards male hormones. Moreover, cytotoxicity of two out of four studied SQAS at the highest concentrations towards the strains of Saccharomyces cerevisiae interfered with the endocrine disruption activity. It would be also worth studying it with the use of another endocrine activity test.
\end{abstract}

Keywords Endocrine disrupting activity $\cdot$ Micropollutants $\cdot$ Quaternary ammonium sophorolipids $\cdot$ Toxicity $\cdot$ Yeast assay

\section{Introduction}

Some natural and synthetic compounds that are able to interfere with the usual functioning of the endocrine system in humans and animals are collectively called endocrine disrupting compounds (EDCs). This group of chemicals mainly consists of natural and synthetic hormones and their metabolites, but also several non-steroidal synthetic compounds that are used as plasticizers, flame retardants,

Ewa Liwarska-Bizukojc

ewa.liwarska-bizukojc@p.lodz.pl

1 Institute of Environmental Engineering and Building Installations, Lodz University of Technology, Al. Politechniki 6, 90-924

Lodz, Poland

2 Faculty of Bioscience Engineering, Department of Green Chemistry and Technology, Ghent University, Coupure Links 653, B-9000 Ghent, Belgium

3 Faculty of Engineering and Architecture, Department of Materials, Textile and Chemical Engineering, Ghent University, Technologiepark 914, B-9052 Ghent-Zwijnaarde, Belgium surfactants and pesticides as well as some pharmaceutical and personal care products (Caliman and Gavrilescu 2009; Hamid and Eskicioglu 2012). Most of them end up in the sewage system after use and finally reach the wastewater treatment plants (WWTPs). Their concentrations in the influent of WWTPs range usually between 0.1 and $10 \mu \mathrm{gl}^{-1}$, so that these chemicals are called micropollutants (Luo et al. 2014). A major contributor to the total estrogenicity of municipal wastewater is the synthetic estrogen $17 \alpha$-ethinylestradiol (EE2), which is widely used in contraceptive pills. Apart from EE2, the highest concentrations in raw municipal wastewater were reported for potential non-steroidal synthetic EDCs such as nonylphenol and diclofenac (Janex-Habibi et al. 2009; Rosal et al. 2010). For example, the reported concentration of diclofenac varied from below 0.001 to $94.2 \mu \mathrm{g} \mathrm{l}^{-1}$ (Kasprzyk-Hordern et al. 2009; Stamatis and Konstantinou 2013; Ruel et al. 2012; Loos et al. 2013; Gao et al. 2014). The fate of micropollutants in WWTPs depends on the individual physicochemical and biological properties of each compound. Ruel et al. (2012) estimated that on average $80 \%$ of the load of micropollutants was removed by conventional activated sludge systems in WWTPs. 
Micropollutants were usually removed from wastewater as a result of sorption and/or microbiological degradation. Sorption onto suspended colloids and particles caused to the removal of these chemicals via waste sludge. According to the classification proposed by Luo et al (2014) human estrogens, EE2, bisphenol A and triclosan were highly removed from wastewater (degree above 70\%); nonylphenol could be classified as moderately removed (degree from 40 to $70 \%$ ), while atrazine and diclofenac were poorly removed (degree below 40\%).

The number of chemicals introduced on the market is still increasing and some of them are classified as environmentally relevant emerging contaminants (Richardson and Ternes 2018). Therefore, it is required to evaluate their physical, chemical and biological properties at the early stage of their life, i.e. before they go into widespread use. Due to thorough studies on chemical properties, it is easier to predict their fate and behaviour in the environment and to avoid threats to living organisms including humans. One of the new classes of chemicals particularly requiring a full description of biological properties, is the class of biosurfactants, namely sophorolipid quaternary ammonium salts.

Sophorolipids are extracellular biosurfactants mainly biosynthesized by yeasts such as Candida bombicola, Candida apicola and Starmerella bombicola. They possess high surface activity, low foaming ability, fast wetting action and low toxicity. Furthermore, they can be completely biodegradable. All these features make sophorolipids an alternative to petrochemical-based surfactants. Nevertheless, their application as detergents is limited due to higher production costs compared to synthetic surfactants. Therefore, other application areas of sophorolipids are looked for.

Sophorolipids, particularly lactonic sophorolipids exhibit antimicrobial activity towards Gram-positive and Gramnegative bacteria (Shah and Badia 2007). Such sophorolipid derivatives as sophorolipids diacetate ethyl esters were reported as the most potent spermicidal and virucidal agents out of those studied by Shah et al. (2005). They also exhibit cytotoxic effects on selected cancer cells (Jing et al. 2006). Custom-built biosurfactants with improved performance, suitable for biomedical applications can be synthesized by chemical and enzymatic modification (Sajna et al. 2015; Delbeke et al. 2016).

An innovative modification pathway of sophorolipids has been described by the Stevens group (Ghent University, Belgium) leading to a new class of biosurfactants, i.e. quaternary ammonium sophorolipids (SQAS). It occurred that some of the new synthesized compounds were more active against bacteria than the antibiotic gentamicin sulfate.

In this work, four SQAS of different chemical composition synthesized by Delbeke et al. (2015) were tested. The criterion of the selection of SQAS was the value of the minimum inhibitory concentration (MIC) determined in tests with Gram-positive and Gram-negative bacteria. The selected SQAS are characterized by minimum inhibitory concentrations at the same or higher level than that of gentamicin.

The main aim of this work was to determine the (anti) estrogenic and (anti)androgenic properties of the representatives of the innovative class of biosurfactants (SQAS), and to compare the results with those obtained for the wellknown micropollutants (diclofenac and $17 \alpha$-ethinylestradiol). Additionally, the toxicity of all tested compounds towards the pure culture of Escherichia coli was checked.

\section{Materials and methods}

\section{Compounds tested}

Four innovative SQAS and two common micropollutants were subjected to tests to determine their endocrine potency and toxicity in this study. SQAS were synthesized at the Department of Green Chemistry and Technology (Ghent University, Belgium). As described in the introduction, the MIC value was assumed as the criterion for the selection of SQAS. The synthesis method and physicochemical properties of the SQAS tested as well as their potential applications were described elsewhere (Delbeke et al. 2015; Delbeke et al. 2016). In view of micropollutant behavior, the compounds were compared to diclofenac and $17 \alpha$-ethinylestradiol. They were purchased from Sigma-Aldrich (SigmaAldrich, Germany) and their purity was not lower than $98 \%$.

Chemical names and structures as well as the codes of all compounds studied are shown in Table 1.

\section{XenoScreen YES/YAS ${ }^{\mathrm{TM}}$ test}

The XenoScreen YES/YAS ${ }^{\mathrm{TM}}$ test, i.e. the Yeast Estrogen Screen (YES)/Yeast Androgen Screen (YAS), was used for the determination of the estrogenic, antiestrogenic, androgenic and antiandrogenic potency of the tested compounds. This test is based on the use of genetically modified strains of Saccharomyces cerevisiae with DNA sequences of human estrogen receptor $(\mathrm{hER} \alpha)$ or human androgen receptor (hAR) that were stably incorporated into the yeast genome (Routledge and Sumpter 1996). Additionally, the cells contain an expression plasmid carrying the reporter gene lac $Z$ encoding for the enzyme $\beta$-galactosidase and estrogen (YES) or androgen (YAS) responsive elements (Routledge and Sumpter 1996; Sohoni and Sumpter 1998).

The activation of the hormone receptors (hER $\alpha$ or hAR) by the binding of an endocrine active substance leads to the expression of $\beta$-galactosidase. The $\beta$-galactosidase is secreted into the medium and converts the yellow substrate 
Table 1 Characteristics of the compounds tested

Chemical name

Mole-cular

Code Chemical structure

weight $\left(\mathrm{g} \mathrm{mol}^{-1}\right)$

N,N-dimethyl,N-octadecyl-( 8 -L-[(2", $3^{\prime}, 3^{\prime \prime}, 4^{\prime}, 4^{\prime \prime}, 6^{\prime}, 6^{\prime \prime}$-heptaacetoxy-

1185

$2^{\prime}$-O- $\beta$-D-glucopyranosyl- $\beta$-D-glucopyranosyl)-oxy])nonan-1

ammonium iodide

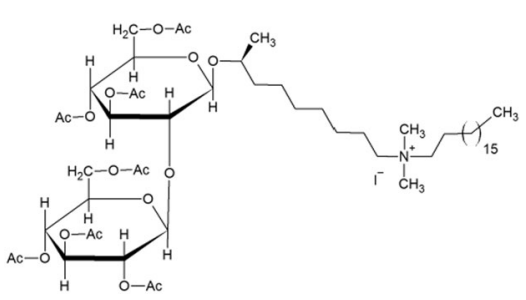

N-benzyl,N-methyl,N-octadecyl-(8-L-[(2" $, 3^{\prime}, 3^{\prime \prime}, 4^{\prime}, 4^{\prime \prime}, 6^{\prime}, 6^{\prime \prime}$

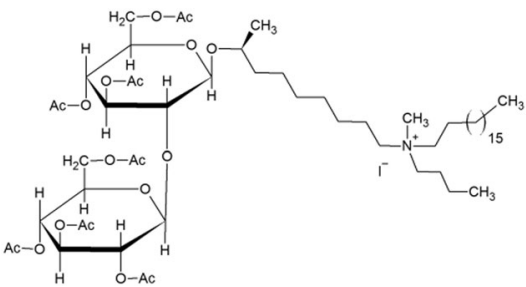

$\mathrm{N}, \mathrm{N}$-dimethyl,N-octadecyl-(8-L-[(2 $\beta-\mathrm{O}-\beta$-D-glucopyranosyl- $\beta$-Dglucopyranosyl)-oxy])nonan-1-ammonium iodide

891

933

N-benzyl,N-methyl,N-octadecyl-(8-L-[(2 $\beta$-O- $\beta$-D-glucopyranosyl$\beta$-D-glucopyranosyl)-oxy])nonan-1-ammonium iodide

[2-(2,6-Dichloroanilin) phenyl]acetic acid

$17 \alpha$-ethinylestradiol

296.40

296.16
SQAS3

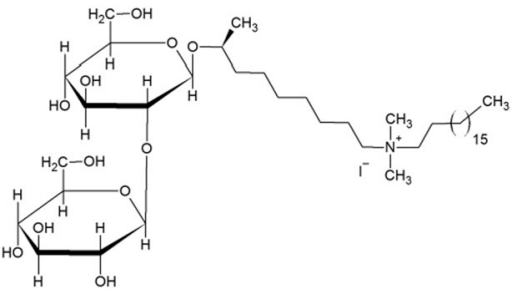

SQAS4

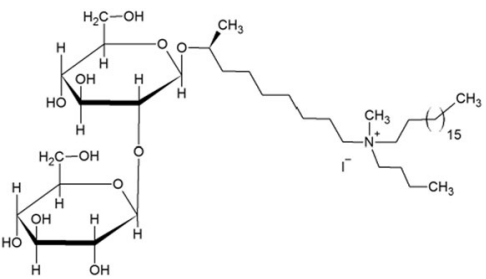

DCF<smiles>O=C(O)Cc1ccccc1Nc1c(Cl)cccc1Cl</smiles>

EE2

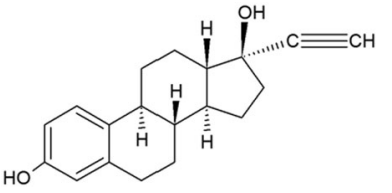

chlorophenol red- $\beta$-D-galactopyranoside (CPRG) into a red product, which can be quantified colorimetrically at $570 \mathrm{~nm}$. Simultaneously, the assay identifies the cytotoxic effects of the tested compounds on yeast cells. Cytotoxic effects lead to growth arrest or lysis of the yeast cells used in the tests. It is measured as a reduction of light scatter at $690 \mathrm{~nm}$. 
The test was carried out according to the instruction delivered by the manufacturer Xenometrix AG (Switzerland). It consisted of six main steps: (1) yeast cultures preparation, (2) preparations and control experiments (17- $\beta$ estradiol (E2) for YES agonists, 4-hydroxytamoxifen (HT) for YES antagonists, 5 $\alpha$-dihydrotestosterone (DHT) for YAS agonists and flutamide (FL) for YAS antagonists) and their transfer to the assay plates, (3) transfer of YES and YAS yeast cells to the assay plates, (4) incubation of the assay plates for $48 \mathrm{~h}$ at $32{ }^{\circ} \mathrm{C}$ in the presence of the substrate for $\beta$-galactosidase on a rotating platform of the orbital shaker MB100-4A at approximately $100 \mathrm{rpm}$, (5) reading the assay plates using a microplate photospectrometer MB530 at 570 and $690 \mathrm{~nm}$, (6) calculation and interpretation of the results towards (anti)estrogenic and (anti)androgenic activity of the tested samples and their cytotoxicity. The individual stock solution for each tested compound in deionized water at the concentration of $10^{-2} \mathrm{M}$ was prepared. Then, it was added to the wells in order to achieve the following final concentrations: $3.16 \cdot 10^{-8}, 1 \cdot 10^{-7}$, $3.16 \cdot 10^{-7}, 1 \cdot 10^{-6}, 3.16 \cdot 10^{-6}, 1 \cdot 10^{-5}, 3.16 \cdot 10^{-5}$ and $1 \cdot 10^{-4}$ M. Each bioassay was repeated four times.

Based upon the measurement of the absorbance, the growth factor $(G)$ and induction $\left(I_{R}\right)$ ratio were calculated from the following equations.

$$
\begin{aligned}
G & =\frac{A_{690, S}}{A_{690, N}} \\
I_{R} & =\frac{1}{G} \cdot \frac{\left(A_{570, S}-A_{690, S}\right)}{\left(A_{570, N}-A_{690, S}\right)}
\end{aligned}
$$

where $\mathrm{A}_{690, \mathrm{~S}}$ and $\mathrm{A}_{570, \mathrm{~S}}$ are the absorbances of samples respectively at 690 and $570 \mathrm{~nm}$ and $A_{690, N}$ and $A_{570, N}$ are the absorbances of the solvent control respectively at 690 and $570 \mathrm{~nm}$.

The growth factor is regarded as the endpoint in the evaluation of cytotoxicity. The value of $\mathrm{G}$ less or equal to 0.5 indicates on possible cytotoxic effects of the compound tested to the yeast cells.

In order to evaluate the results, the criterion was adopted that the tested sample has agonistic YES/YAS properties if the value of $I_{R} \geq 1.5$ (for control solutions) and has antagonistic YES/YAS properties if the value of $\mathrm{I}_{\mathrm{R}} \leq 66.7 \%$ of the value obtained for the control sample (Szczepańska et al. 2018). It was called the IR criterion in this work.

The values of estrogen equivalent (EEQ) and androgen equivalent (AEQ) were calculated. They correspond to the concentration of E2 and DHT, respectively, which would give the same activity as the sample tested. The calculations were made if the equivalent concentration was not lower than $10^{-10} \mathrm{M}$ in the YES tests or $10^{-9} \mathrm{M}$ in the YAS tests. For antiestrogenic and antiandrogenic potency, these equivalent concentrations were called aEEQ or aAEQ, respectively.

Additionally, the values of the effective concentrations (EC50) were determined. In the agonist assays EC50 means the effective concentration at $50 \%$ of $\mathrm{I}_{\mathrm{R}, \mathrm{MAX}}$, where $\mathrm{I}_{\mathrm{R}, \mathrm{MAX}}$ is the highest $I_{R}$ of the compound at a non-toxic concentration. At the same time in the antagonist assay, the value of EC50 was calculated only if the percentage of $I_{R}$, MIN relative to the fitted $I_{R}$ was equal or lower than $50 \%$, where $I_{R, M I N}$ is the lowest $I_{R}$ at the non-toxic concentration of the compound tested.

\section{Determination of toxicity towards Escherichia coli}

In order to determine the toxicity of the compounds tested towards bacteria, the ToxTrak ${ }^{\mathrm{TM}}$ method was applied. This method is based on the reduction of resazurin, a redox-active dye, by bacterial respiration. When it is reduced, resazurin changes color from blue to pink. Toxic substances can inhibit the rate of resazurin reduction, what can be measured colorimetrically. The endpoint of the ToxTrak ${ }^{\mathrm{TM}}$ method is the inhibition of the bacterial respirometric activity expressed as the degree of inhibition (\%). In agreement with the guidelines of the manufacturer, it was assumed that the degree of inhibition equal to $10 \%$ correlates with the Lowest Observable Effect Concentration (LOEC).

In this work, the ToxTrak ${ }^{\mathrm{TM}}$ test was used to measure the toxicity of the compounds tested towards the pure culture of bacteria Escherichia coli DSM 30083. Each of the compounds was tested individually. The absorbance was measured with the use of a spectrophotometer DR 6000 at $\lambda=603 \mathrm{~nm}$. The test was made in accordance to the guidelines for ToxTrak ${ }^{\mathrm{TM}}$ (Toxicity ToxTrak ${ }^{\mathrm{TM}}$ Method 10017, HACH LANGE manual. https:/www.hach.com/toxtrak-reagent-pk-50-powder-pillows/ product-parameter-reagent id $=7640273472 \&$ callback $=q s$ ). Each sample was analyzed in four replicates.

\section{Results and discussion}

In this work (anti)estrogenic and (anti)androgenic properties of the chemicals were evaluated with the use of two criteria. These were the EC50 values (Table 2) and the relation between the $I_{R}$ of the tested sample and the control sample, together with the values of the equivalent concentrations (Table 3). If any compound revealed agonistic or antagonistic endocrine activity according to the IR criterion it was indicated by the sign "+" in Table 3. If not, the sign "--" was used.

\section{Estrogenic and androgenic activities}

It was found that none of the newly synthesized biosurfactants (SQAS) exhibited agonistic properties in relation 
Table 2 Values of the effective concentration (EC50) assessed for the compounds tested including the control substances

\begin{tabular}{|c|c|c|c|}
\hline $\begin{array}{l}\text { Type of } \\
\text { endocrine } \\
\text { activity }\end{array}$ & Compound & EC50 $[\mathrm{M}]$ & $R^{2}$ \\
\hline \multirow[t]{7}{*}{ YES agonist } & 17ß-estradiol (E2) & $2.12 \cdot 10^{-10}$ & 0.978 \\
\hline & SQAS1 & $\mathrm{n} / \mathrm{d}$ & $\mathrm{n} / \mathrm{d}$ \\
\hline & SQAS2 & $\mathrm{n} / \mathrm{d}$ & $\mathrm{n} / \mathrm{d}$ \\
\hline & SQAS3 & $\mathrm{n} / \mathrm{d}$ & $\mathrm{n} / \mathrm{d}$ \\
\hline & SQAS4 & $\mathrm{n} / \mathrm{d}$ & $\mathrm{n} / \mathrm{d}$ \\
\hline & DCF & $1.50 \cdot 10^{-4 a}$ & 0.998 \\
\hline & EE2 & $4.40 \cdot 10^{-6}$ & 0.906 \\
\hline \multirow[t]{7}{*}{ YAS agonist } & $5 \alpha$-dihydrotestosterone (DHT) & $8.02 \cdot 10^{-9}$ & 0.985 \\
\hline & SQAS1 & $\mathrm{n} / \mathrm{d}$ & $\mathrm{n} / \mathrm{d}$ \\
\hline & SQAS2 & $\mathrm{n} / \mathrm{d}$ & $\mathrm{n} / \mathrm{d}$ \\
\hline & SQAS3 & $\mathrm{n} / \mathrm{d}$ & $\mathrm{n} / \mathrm{d}$ \\
\hline & SQAS4 & $\mathrm{n} / \mathrm{d}$ & $\mathrm{n} / \mathrm{d}$ \\
\hline & $\mathrm{DCF}$ & $\mathrm{n} / \mathrm{d}$ & $\mathrm{n} / \mathrm{d}$ \\
\hline & EE2 & $\mathrm{n} / \mathrm{d}$ & $\mathrm{n} / \mathrm{d}$ \\
\hline \multirow[t]{7}{*}{ YES antagonist } & 4-Hydroxytamoxifen (HT) & $6.92 \cdot 10^{-8}$ & 0.994 \\
\hline & SQAS1 & $9.70 \cdot 10^{-5 a}$ & 0.663 \\
\hline & SQAS2 & $1.70 \cdot 10^{-4 a}$ & 0.704 \\
\hline & SQAS3 & $\mathrm{n} / \mathrm{d}$ & $\mathrm{n} / \mathrm{d}$ \\
\hline & SQAS4 & $\mathrm{n} / \mathrm{d}$ & $\mathrm{n} / \mathrm{d}$ \\
\hline & DCF & $3.00 \cdot 10^{-7}$ & 0.729 \\
\hline & EE2 & $6.50 \cdot 10^{-7}$ & 0.802 \\
\hline \multirow[t]{7}{*}{ YAS antagonist } & flutamide (FL) & $6.78 \cdot 10^{-6}$ & 0.966 \\
\hline & SQAS1 & $5.10 \cdot 10^{-5 a}$ & 0.997 \\
\hline & SQAS2 & $1.70 \cdot 10^{-4 a}$ & 0.722 \\
\hline & SQAS3 & $7.90 \cdot 10^{-7 a}$ & 0.691 \\
\hline & SQAS4 & $\mathrm{n} / \mathrm{d}$ & $\mathrm{n} / \mathrm{d}$ \\
\hline & DCF & $7.5 \cdot 10^{-8 a}$ & 0.702 \\
\hline & EE2 & $1.3 \cdot 10^{-6 a}$ & 0.710 \\
\hline
\end{tabular}

${ }^{\mathrm{a}}$ The extrapolated values to either estrogenic or androgenic hormonal activities (Tables 2 and 3). In the case of two SQAS, namely SQAS1 and SQAS2 this was confirmed by both criteria used in this work (Tables 2 and 3). At the same time the other two biosurfactants (SQAS3 and SQAS4) showed agonistic properties related to the male hormone according to the IR criterion (Table 3). However, the values of equivalent concentrations (AEQ) could not be determined for SQAS3 and SQAS4 with respect to their agonistic androgen activity. The problems with the determination of the equivalent concentrations and the values of EC50 were most probably connected with the cytotoxicity of SQAS3 and SQAS4 towards YAS yeast cells at the two highest concentrations tested. The toxicity trumped the endocrine disruption activity, and therefore it is difficult to judge, whether SQAS3 and SQAS4 can be classified as androgen agonists.

The cytotoxicity of SQAS also contributed to some problems to achieve the highest degrees of correlation of the experimental points to the sigmoidal dose-response curve. The values of the degree of correlation $\left(R^{2}\right)$ were usually lower in the experiments with SQAS than in these with DCF or EE2 (Table 2). However, they were at the similar level to those determined by Czernych et al. (2017) for the results of the same tests (YES/YAS tests). What is more important, for all controls the values of $R^{2}$ were from 0.966 to 0.994 (Table 2), which indicated on the correctness of the performed bioassays.

With regard to the second group of chemicals tested, i.e. the common micropollutants (DCF and EE2), it was found that each of them possessed agonistic activity towards female hormones. It was confirmed by both criteria used in this study. The EC50 values determined for EE2 and DCF were, respectively, four and six orders of magnitude, higher compared to the value of EC50 obtained for the E2 control, i.e. $2 \cdot 12 \cdot 10^{-10} \mathrm{M}$ (Table 2). It indicated that EE2 and DCF were significantly less potent to activate the estrogen

Table 3 (Anti)estrogenic and (anti)androgenic activities of the compounds tested based upon the IR criterion. The values of the equivalent concentrations

\begin{tabular}{|c|c|c|c|c|c|c|c|c|}
\hline \multirow[t]{3}{*}{ Compound } & \multicolumn{4}{|c|}{ Estrogenic activity } & \multicolumn{4}{|c|}{ Androgenic activity } \\
\hline & \multicolumn{2}{|c|}{ Agonistic estrogenic activity } & \multicolumn{2}{|c|}{$\begin{array}{l}\text { Antagonistic estrogenic } \\
\text { activity }\end{array}$} & \multicolumn{2}{|c|}{$\begin{array}{l}\text { Agonistic androgenic } \\
\text { activity }\end{array}$} & \multicolumn{2}{|c|}{$\begin{array}{l}\text { Antagonistic androgenic } \\
\text { activity }\end{array}$} \\
\hline & $I_{R}$ criterion & EEQ $[\mathrm{M}]$ & $I_{R}$ criterion & aEEQ [M] & $I_{R}$ criterion & AEQ $[\mathrm{M}]$ & $I_{R}$ criterion & aAEQ $[\mathrm{M}]$ \\
\hline SQAS1 & - & $<10^{-10}$ & - & $8.67 \cdot 10^{-4}$ & - & $<10^{-9}$ & - & $<10^{-9}$ \\
\hline SQAS2 & - & $<10^{-10}$ & - & $5.1 \cdot 10^{-4}$ & - & $<10^{-9}$ & - & $8.23 \cdot 10^{-2} \pm 0.02$ \\
\hline SQAS3 & - & $<10^{-10}$ & - & $<10^{-10}$ & + & $<10^{-9}$ & + & $<10^{-9}$ \\
\hline SQAS4 & - & $<10^{-10}$ & - & $<10^{-10}$ & + & $<10^{-9}$ & - & $<10^{-9}$ \\
\hline DCF & + & $1.19 \cdot 10^{-6}$ & + & $1.8 \cdot 10^{-1} \pm 0.25$ & - & $<10^{-9}$ & + & $<10^{-9}$ \\
\hline EE2 & + & $3.9 \cdot 10^{-5} \pm 0.82 \cdot 10^{-5}$ & + & $8.3 \cdot 10^{-2} \pm 0.14$ & - & $<10^{-9}$ & + & $5.29 \pm 5.10$ \\
\hline
\end{tabular}

"+" indicates on agonistic or antagonistic endocrine activity according to the $\mathrm{I}_{\mathrm{R}}$ criterion; "-" indicates on neither agonistic nor antagonistic endocrine activity according to the $\mathrm{I}_{\mathrm{R}}$ criterion 
receptor than E2. Also the results shown in Table 3 confirmed that DCF and EE2 were able to activate the estrogen receptor, and thus have been classified as xenoestrogens. EE2 is a synthetic estrogen hormone and its hormonal potency was many times verified in the estrogenic/androgenic bioassays in order to check the correctness and/or to optimize these assays (Ternes et al. 1999; Bistan et al. 2012).

\section{Antiestrogenic and antiandrogenic activities}

Regarding the antagonistic (inhibiting) activities of the compounds tested to the hormone receptors, the following observations were made.

With respect to the antiestrogenic activity the EC50 values were obtained for two SQAS, DCF and EE2 (Table 2). Among the SQAS, SQAS1 and SQAS2 revealed antiestrogenic potential, however it was significantly lower (three and four orders of magnitude, respectively) than that determined for the 4-HT control, for which the EC50 value was equal to $0.0692 \cdot \mathrm{M}$. It was also lower than the antiestrogenic activity found for DCF and EE2 (Table 2). It should be noticed that the EC50 values for SQAS1 and SQAS2 were extrapolated and their antiestrogenic potency was not confirmed by the IR criterion (Table 3). At the same time DCF and EE2 revealed antiestrogenic activity but at the highest tested concentration tested. Nevertheless, it indicated that they can interact both as agonists and antagonists with the human estrogen receptor.

The study of the antiandrogenic activity, in particular the EC50 values, demonstrated that three out of six compounds studied exerted significant inhibitory effect comparable or exceeding the inhibitory activity of the positive control, i.e. FL. It was clearly observed for SQAS3, DCF and EE2 (Table 2). In the case of SQAS1 and SQAS2, the EC50 values were respectively one and two orders of magnitude higher than that determined for FL $\left(\mathrm{EC} 50=6.78 \cdot 10^{-6} \mathrm{M}\right.$ for FL) indicating a much weaker inhibitory effect compared to FL (Table 2). At the same time the strongest inhibitory properties were found for SQAS3 and DCF. The EC50 values determined for these compounds were respectively 10-fold and 100-fold, lower than the EC50 value calculated for FL (Table 2). The antiandrogenic potency of SQAS3 and DCF was also confirmed by the IR criterion (Table 3). Regarding SQAS4 it was found that this compound revealed no antiandrogenic activity according to both criteria used (Tables 2 and 3).

EE2 occurred to be an antagonist of androgens as well (Tables 2 and 3). The observations are in agreement with the fact that many xenoestrogens demonstrate antiandrogenic activity (Sohoni and Sumpter 1998). DCF and some of its metabolites were regarded as estrogenic and antiandrogenic compounds (Klopčič et al. 2018). In this work estrogenic activity of EE2 and DCF was primarily reported. Nevertheless, it occurred that they can interact both as agonists and antagonists with the human estrogen/androgen receptors. This study proves that DCF and EE2 belong to hormonemimicking chemicals of multiple hormonal activities.

\section{Toxicities towards yeast cells and Escherichia coli}

Simultaneously with the determination of the (anti)estrogenic and (anti)androgenic activity of the compounds tested, their cytotoxicity to the strains of Saccharomyces cerevisiae was measured. The values of growth factor for YES and YAS yeast cells are depicted in Fig. 1. Based upon them it was found that all SQAS exerted cytotoxic effects towards cells of any of the genetically modified YES or YAS yeast strains, whereas DCF and EE2 did not show any cytotoxic properties (Fig. 1). SQAS3 and SQAS4 exerted toxic effects towards both YES and YAS yeast cells at two highest concentrations tested $(\mathrm{G} \leq 0.5)$, while SQAS1 and SQAS2 were toxic towards YAS yeast cells only at the highest concentration tested $(\mathrm{G} \leq$ $0.5)$. It shows that SQAS1 and SQAS2 were less toxic towards the strains of Saccharomyces cerevisiae than SQAS3 and SQAS4. The most likely reason of this behavior of SQAS is the acetylation of the hydroxyl groups of the carbohydrate head in the case of SQAS1 and SQAS2 (Table 1). It decreases the cytotoxicity of this class of biosurfactants and contributes to the decrease of their endocrine potency as well.

The toxicity of the studied chemicals towards bacteria Escherichia coli was evaluated using the LOEC as estimator. The values of LOEC varied from $1.07 \cdot 10^{-4}$ to $3.37 \cdot 10^{-4} \mathrm{M}$ and despite the difference between them, it should be noticed that all represent the same order of magnitude (Fig. 2). It was found that SQAS3 and SQAS4 might exert a stronger effect on the respiration activity of $E$. coli than the other compounds tested. Regarding the chemical structure of SQAS tested, it occurred that the acetylation of the hydroxyl groups of the carbohydrate head of SQAS caused a decrease of toxicity towards $E$. coli as well. Delbeke et al. (2015) reported that the MIC values for the studied SQAS ranged between $5 \cdot 10^{-6}$ and $8 \cdot 10^{-6} \mathrm{M}$ towards the following bacteria Bacillus subtilis, Staphylococcus aureus, Enterococcus faecium and Streptococcus pneumoniae. The lower MIC values indicating a higher toxicity were found for SQAS3 and SQAS4 in comparison to SQAS1 and SQAS2 (Delbeke et al. 2015). The results obtained in this work for SQAS towards E. coli are consistent with findings of Delbeke et al. (2015). Out of all biosurfactants studied here SQAS2 turned to be the least toxic followed by SQAS1, SQAS3 and SQAS4 (Fig. 2).

Moreover, it was found that DCF showed relatively strong, actually stronger than EE2, impact on the biochemical activity of bacteria (Fig. 2), while it did not inhibit the growth of the yeasts used in the YES/YAS assays. It proved that the effect of the same compound depended on the sensitivity of the organism which was exposed to it. 
YES yeast cells
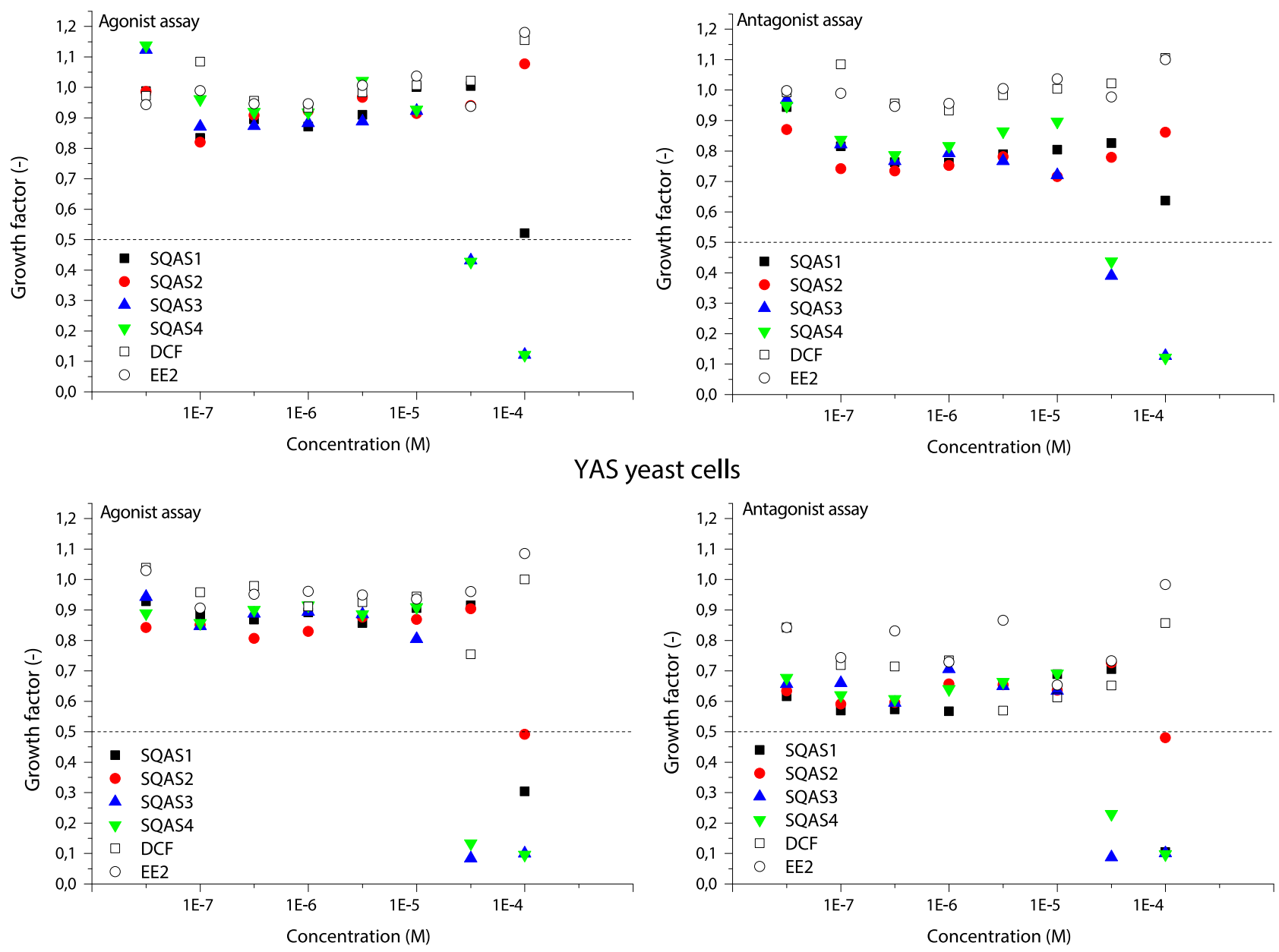

Fig. 1 The values of growth factor for YES yeast cells (top panels) and YAS yeast cells (bottom panels)

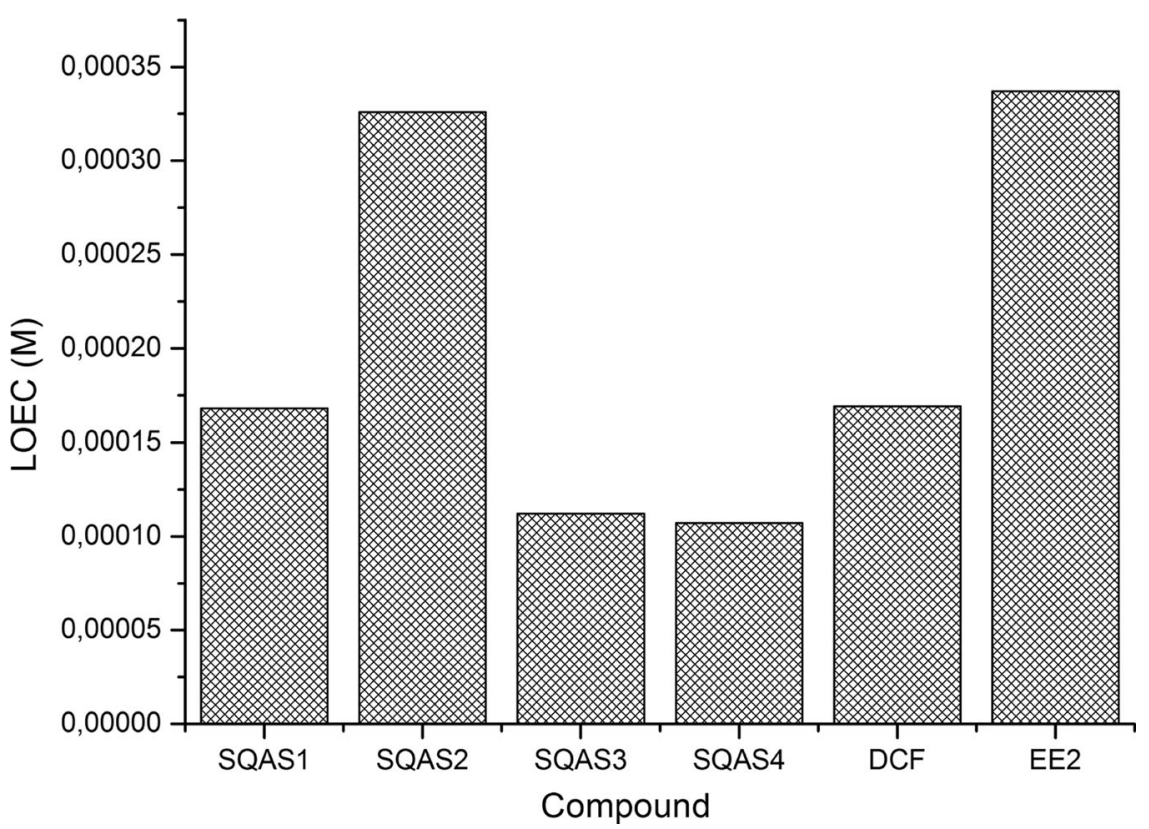

Fig. 2 Effect of SQAS, DCF and EE2 on respiration activity of Escherichia coli Springer 
However, the number of data concerning the effect of SQAS on the organisms is very small and primarily limited to bacteria and yeasts. It makes the evaluation of the possible impacts of this class of biosurfactants on the biota difficult. So before introducing of SQAS to the market, the ecotoxicity studies should be extended and comprise other organisms representing different trophic levels.

\section{Conclusions}

1. None of SQAS studied is most likely an agonist of female or male hormones. SQAS3 shows relatively strong inhibitory activity towards male hormones. SQAS1 and SQAS2 reveal weak antiestrogenic and antiandrogenic potency based upon the values of EC50. Each of these properties is weaker than the potency of the appropriate positive control in the antagonists assays but also compared to the potency of other tested compounds, i.e. DCF and EE2.

2. The unequivocal evaluation of the endocrine potency of the SQAS studied is not an easy task due to their toxic effect at the highest concentrations on the strains of Saccharomyces cerevisiae used in the YES/YAS assays. Two out of four SQAS, namely SQAS3 and SQAS4, show cytotoxicity towards both YES and YAS yeast cells at the two highest concentrations tested. SQAS1 and SQAS2 are toxic only towards YAS yeast cells at the highest concentration tested.

3. This work demonstrates that the acetylation of the hydroxyl groups of the carbohydrate head of SQAS decreases the toxicity of these biosurfactants towards Saccharomyces cerevisiae and contribute to the decrease of their endocrine potency too.

\section{Data availability}

Data presented in this study are available on request from the corresponding author.

Funding This work was financially supported by Water Supply System and Sewer-Zgierz Ltd., Zgierz (Poland).

Author contributions ELB - study concept and design, bioassays performance and supervision, elaboration and interpretation of results, preparation of the paper; CVS - the substantive support in the preparation of the paper, supervision on the synthesis of sophorolipid biosurfactants; EIPD, KMVG-synthesis and evaluation of the properties of sophorolipid biosurfactants.

\section{Compliance with ethical standards}

Conflict of interest The authors declare no competing interests.
Consent for publication All authors consent for publication of this paper.

Consent to participate All authors consent to participate in the study.

Publisher's note Springer Nature remains neutral with regard to jurisdictional claims in published maps and institutional affiliations.

Open Access This article is licensed under a Creative Commons Attribution 4.0 International License, which permits use, sharing, adaptation, distribution and reproduction in any medium or format, as long as you give appropriate credit to the original author(s) and the source, provide a link to the Creative Commons license, and indicate if changes were made. The images or other third party material in this article are included in the article's Creative Commons license, unless indicated otherwise in a credit line to the material. If material is not included in the article's Creative Commons license and your intended use is not permitted by statutory regulation or exceeds the permitted use, you will need to obtain permission directly from the copyright holder. To view a copy of this license, visit http://creativecommons. org/licenses/by/4.0/.

\section{References}

Bistan M, Podgorelec M, Logar RM, Tišler T (2012) Yeast estrogen screen assay as a tool for detecting estrogenic activity in water bodies. Food Technol Biotechnol 50(4):427-433

Caliman FA, Gavrilescu M (2009) Pharmaceuticals, personal care products and endocrine disrupting agents in the environment: a review. Clean-Soil Air Water 37(4-5):277-303. https://doi.org/ 10.1002/clen.200900038

Czernych R, Chraniuk M, Zagożdźon P, Wolska L (2017) Characterization of estrogenic and androgenic activity of phthalates by the XenoScreen YES/YAS in vitro assay. Environ Toxicol Pharmacol 53:95-104. https://doi.org/10.1016/j.etap.2017.05.010

Delbeke EIP, Roman BI, Marin GB, Van Geem KM, Stevens CV (2015) A new class of antimicrobial biosurfactants: quaternary ammonium sophorolipids. Green Chem 17:3373-3377. https:// doi.org/10.1039/c5gc00120j

Delbeke EIP, Movsisyan M, Van Geem KM, Stevens CV (2016) Chemical and enzymatic modification of sophorolipids. Green Chem 18:76-104. https://doi.org/10.1039/C5GC02187A

Gao D, Li Z, Wen Z, Ren N (2014) Occurrence and fate of phthalate esters in full-scale domestic wastewater treatment plants and their impact on receiving waters along the Songhua River in China. Chemosphere 95:24-32. https://doi.org/10.1016/j.chemosphere.2013.08.009

Hamid H, Eskicioglu C (2012) Fate of estrogenic hormones in wastewater and sludge treatment: a review of properties and analytical detection techniques in sludge matrix. Water Res 46:5813-5833. https://doi.org/10.1016/j.watres.2012.08.002

Janex-Habibi ML, Huyard A, Esperanza M, Bruchet A (2009) Reduction of endocrine disruptor emissions in the environment: the benefit of wastewater treatment. Water Res 43:1565-1576. https://doi.org/10.1016/j.watres.2008.12.051

Jing CH, Xin S, Hui Z, Yinbo Q (2006) Production, structure elucidation and anticancer properties of sophorolipids from Wickerhamiella domercqiae. Enz Microbial Technol 39:501-506. https://doi.org/10.1016/j.enzmictec.2005.12.022

Kasprzyk-Hordern B, Dinsdale RM, Guwy AJ (2009) The removal of pharmaceuticals, personal care products, endocrine disruptors and illicit drugs during wastewater treatment and its impact on the quality of receiving waters. Water Res 43:363-380. https://doi. org/10.1016/j.watres.2008.10.047 
Klopčič I, Markovič T, Mlinarič-Raščan I, Sollner Dolenc M (2018) Endocrine disrupting activities and immunomodulatory effects in lymphoblastoid cell lines of diclofenac, 4-hydroxydiclofenac and paracetamol. Toxicol Lett 294:95-104. https://doi.org/10.1016/j. toxlet.2018.05.022

Loos R, Carvalho R, António DC, Comero S, Locoro G, Tavazzi S, Paracchini B, Ghiani M, Lettieri T, Blaha L, Jarosova B, Voorspoels S, Servaes K, Haglund P, Fick J, Lindberg RH, Schwesig D, Gawlik BM (2013) EU-wide monitoring survey on emerging polar organic contaminants in wastewater treatment plant effluents. Water Res 47:6475-6487. https://doi.org/10.1016/j.watres. 2013.08.024

Luo Y, Guo W, Ngo HH, Nghiem LD, Hai FI, Zhang J, Liang S, Wang XC (2014) A review on the occurrence of micropollutants in the aquatic environment and their fate and removal during wastewater treatment. Sci Total Environ 473-474:619-641. https://doi.org/10.1016/j.scitotenv.2013.12.065

Richardson SD, Ternes TA (2018) Water analysis: emerging contaminants and current issues. Anal Chem 90:398-428. https://doi. org/10.1021/acs.analchem.7b04577

Rosal R, Rodríguez A, Perdigón-Melón JA, Petre A, García-Calvo E, Gómez MJ, Agüera A, Fernández-Alba AR (2010) Occurrence of emerging pollutants in urban wastewater and their removal through biological treatment followed by ozonation. Water Res 44:578-588. https://doi.org/10.1016/j.watres.2009. 07.004

Routledge EJ, Sumpter JP (1996) Estrogenic activity of surfactants and some of their degradation products assessed using a recombinant yeast screen. Environ Toxicol Chem 15/3:241-248. https://doi. org/10.1002/etc.5620150303

Ruel SM, Choubert JM, Budzinski H, Miège C, Esperanza M, Coquery M (2012) Occurrence and fate of relevant substances in wastewater treatment plants regarding Water Framework
Directive and future legislations. Water Sci Technol 65 (7):1179-1188. https://doi.org/10.2166/wst.2012.943

Sajna KV, Höfer R, Sukumaran RK, Gottumukkala LD, Pandey A (2015) White biotechnology in biosurfactants. In: Pandey A, Höfer R, Taherzadeh M, Nampoothiri KM, Larroche C (Eds) Industrial Biorefineries and White Biotechnology, Elsevier, Amsterdam, Oxford, Waltham pp. 499-521

Shah V, Badia D (2007) Sophorolipids having enhanced antibacterial activity. Antimicrobial Agents Chemother 51:397-400. https:// doi.org/10.1128/AAC.01118-06

Shah V, Doncel GF, Seyoum T, Eaton KM, Zalenskaya I, Hagver R et al. (2005) Sophorolipids, microbial glycolipids with antihuman immunodeficiency virus and sperm-immobilizing activities. Antimicrob Agents Chemother 49:4093-100. https://doi. org/10.1128/AAC.49.10.4093-4100.2005

Sohoni P, Sumpter JP (1998) Several environmental oestrogens are also anti-androgens. J Endocrinol 158:327-339. https://doi.org/ 10.1677/joe.0.1580327

Stamatis N, Konstantinou I (2013) Occurrence and removal of emerging pharmaceutical, personal care compounds and caffeine tracer in municipal sewage treatment plant in Western Greece. J Environ Sci Health B 48:800-813. https://doi.org/10.1080/ 03601234.2013.781359

Szczepańska N, Kudłak B, Tsakovski S, Yotova G, Nedyalkova M, Simeonov V, Dołęga A, Namieśnik J (2018) Modeling and MANOVA studies on toxicity and endocrine potential of packaging materials exposed to different extraction schemes. Environ Res 165:294-305. https://doi.org/10.1016/j.envres.2018.05.004

Ternes TA, Stumpf M, Mueller J, Haberer K, Wilken RD, Servos M (1999) Behavior and occurrence of estrogens in municipal sewage treatment plants-I. Investigations in Germany, Canada and Brazil. Sci Total Environ 225:81-90. https://doi.org/10.1016/ s0048-9697(98)00334-9 